\title{
Recovery of visual pattern discrimination by rats without visual cortex when trained by fading procedure
}

\author{
ELIANA GUIC-ROBLES, NANCY VENABLE, ISABEL ACEVEDO, \\ BEATRIZ ARAMBURU, and TERESA PINTO-HAMUY \\ Universidad de Chile, Santiago, Chile
}

\begin{abstract}
The effects of two training and two surgical procedures on the recovery of a visual pattern discrimination were compared in rats with visual cortex damage (areas 17, 18, and 18a). Normal control subjects and rats with serial or simultaneous visual cortex lesions were first trained on a brightness (black vs. white) discrimination task and then on a pattern (horizontal vs. vertical stripes) discrimination task by either classical or fading procedures. The rats' performance in the preoperative, interoperative, and postoperative stages of training were compared. Rats with serial lesions showed postoperative savings in the brightness task and relearned the pattern discrimination task when trained by either the fading or the classical method. Serially lesioned subjects presented fewer errors to criterion when trained by the fading procedure than when trained by the classical procedure. Rats with simultaneous lesions showed no savings on the brightness discrimination task and all of the subjects in this group relearned the pattern discrimination task when trained by the fading procedure. Simultaneously lesioned subjects trained to a maximum of 750 trials using the classical method did not relearn the pattern discrimination task, except for one subject. Interaction between the surgical and training variables is discussed.
\end{abstract}

It has long been known that, after simultaneous bilateral removal of the visual cortex (areas 17, 18, and 18a, as defined by Krieg, 1946a, 1946b) or all the posterior half of the cortex, rats are able to relearn a black vs. white (B-W) brightness discrimination task (Barbas \& Spear, 1976; Bauer \& Cooper, 1964; Glendenning, 1972; Hamilton \& Trichler, 1969; Horel, Bettinger, Royce, \& Meyer, 1966; Lashley, 1935, 1937; LeVere \& Morlock, 1973; Meyer, Yutzey, \& Meyer, 1966; Petrinovich \& Carew, 1969; Thompson, 1960). Such rats, however, are not able to reacquire a horizontal vs. vertical (H-V) pattern discrimination task (Bauer \& Hughes, 1970; Bland \& Cooper, 1969; Braun, Lundy, \& McCarthy, 1970; Lashley, 1931; Spear \& Barbas, 1975; Thompson, 1969). If the bilateral lesion is serially made, that is, in sequential operations, the subjects show savings on the brightness discrimination (Glendenning, 1972; Petrinovich \& Bliss, 1966; Petrinovich \& Carew, 1969; Scheff, Wright, Morgan, \& Powers, 1977; Scheff \& Wright,

The authors would like to thank Fernando Torrealba for his invaluable advice on the surgical and histological work and Luis Robles for his helpful suggestions and comments on the manuscript. This research was supported by the Servicio de Desarrollo Científico, Artístico y de Cooperación Internacional, Universidad de Chile (Projects B 164-815-F and B 1215-811-3). Correspondence should be directed to E. Guic-Robles, Departmento de Fisiologia y Biofisica, Facultad de Medicina, Santiago Norte, Universidad de Chile, Casilla 137-D Correo Central, Santiago, Chile.
1977; Thompson, 1960) and can relearn an H-V discrimination (Dru, Walker, \& Walker, 1975a, 1975b; Spear \& Barbas, 1975). This facilitating phenomenon is shown only if the rats are subjected to adequate visual stimulation (Dru, Walker, \& Walker, 1975a, 1975b) or practice (Glendenning, 1972; Petrinovich \& Carew, 1969; Thompson, 1960) during the interlesion period. The serial lesion effect has been demonstrated in adult subjects from a variety of species tested on different sensory modality tasks (see Finger, Walbran, \& Stein, 1973, for review).

The training method used in all the recovery experiments cited above can be characterized as one in which subjects are presented with discriminanda that remain invariant throughout training. Comparative studies between classical and fading procedures have indicated that training procedure may be a critical variable. In the fading procedure, the subjects are initially confronted with an easy or previously learned discrimination task that is gradually transformed into a more difficult one. It has been demonstrated that the fading procedure, as compared with the classical method, facilitates the acquisition or transfer of discrimination tasks in both human (Barlow \& Agras, 1973; Corey \& Shamow, 1973; Dorry, 1976; May \& MacPherson, 1971; Moore \& Goldiamond, 1964; Sidman \& Stoddard, 1967; Touchett, 1968; Wulbert, Nyman, Snow, \& Owen, 1973) and animal subjects (Brown \& Rilling, 1975; Ellen, Dorsett, \& Richardson, 1977; Lawrence, 1952; MacDonald \& Macucella, 
1976; Schlosberg \& Solomon, 1943; Schusterman, 1966, 1967; Stettner \& Matyniak, 1969; Terrace, $1963 \mathrm{a}, 1963 \mathrm{~b})$. Specifically, normal rats trained by fading learned a visual pattern discrimination task with fewer trials and errors than did subjects trained by the classical method (Aronsohn, Castillo, \& PintoHamuy, 1978; Guić, Aronsohn, Gormaz, \& PintoHamuy, 1978). The purpose of the present experiment was to determine whether rats with simultaneous visual cortex lesions could relearn the $\mathrm{H}-\mathrm{V}$ task when trained by the fading procedure. We first trained the rats in a B-W discrimination task; subsequently, the brightness cue was superimposed upon the pattern cue and then gradually faded out. In addition, we were interested in studying the possible interaction between the two facilitating conditions previously mentioned, that is, serial lesions and fading procedure.

\section{METHOD}

\section{Subjects}

The subjects were 40 naive adult male Long-Evans hooded rats, 90-120 days old at the beginning of the experiment. They were housed four per cage $(46 \times 32 \times 18 \mathrm{~cm})$ with ad-lib food and water. Illumination was on a 12:12 daily light-dark schedule.

\section{Apparatus and Training}

A semiautomated two-choice avoidance box, similar to that described by Thompson and Bryant (1955), was used for discrimination training. It was constructed of black acrylic plastic and consisted of a startbox (10 cm wide $\times 20 \mathrm{~cm}$ long), a choice box (40 cm long, with steadily increasing width from $10 \mathrm{~cm}$ at the startbox to $30 \mathrm{~cm}$ at the choice point), and a goalbox $(30 \times 30 \mathrm{~cm})$. The startbox was separated from the choice compartment by a guillotine door. The choice and goalboxes were intercommunicated by two $9 \times 9 \mathrm{~cm}$ apertures, $8.5 \mathrm{~cm}$ apart, in which swing stimulus doors were inserted. Between the two apertures there was a partition that projected $7 \mathrm{~cm}$ into the choice box. The floor of the apparatus consisted of a bronze grid. The grid of the startbox, of the choice compartment, and of the $7-\mathrm{cm}$ sections contiguous to each stimulus door could be independently electrified (.2$.4 \mathrm{~mA}$ ). Two $220-\mathrm{V}$ and $6-\mathrm{W}$ bulbs mounted above the stimulus doors provided the only illumination during training.

The rats were initially habituated to the apparatus, being allowed $25 \mathrm{~min}$ of free exploration with no doors present. The next day, with gray doors inserted, the subjects were pretrained to escape and avoid shock. They were required to run from the startbox into the choice box within $5 \mathrm{sec}$ and from the choice compartment into the goal compartment within $30 \mathrm{sec}$ for five consecutive trials. During this and all further phases of training, a failure to make the running response before the preset time resulted in footshock, which continued until the animal made the escape response. During pretraining, no more than three successive responses were permitted to one side; this was accomplished by locking the door and charging the grid on the favored side. The rats were trained to push the stimulus doors by initially placing the doors over only the upper third of the openings and gradually lowering them until they fully covered the apertures. When discrimination training began, the gray stimulus doors were replaced by the discriminanda. A trial started when the experimenter lifted the guillotine door, after the animal was placed in the startbox. During training, the grid was electrified $7 \mathrm{~cm}$ in front of the locked negative stimulus (S-) and the grid in front of the unlocked positive doors
(S+) was not. The rats were required to run from the startbox through the choice compartment and into the goalbox via the $\mathrm{S}+$ stimulus door. If the subjects stepped within the 7-cm section in front of the $\mathrm{S}-$ door, they received footshocks and an error was recorded. If an incorrect choice was made, the rat was allowed to shift and enter the goalbox through the $\mathrm{S}+$ door. Following each trial, the rats were removed from the goalbox and transferred to an individual cage for an intertrial interval of at least $2 \mathrm{~min}$. The position of the discriminanda was varied from left to right on each trial according to different sets of Gellerman series (Gellerman, 1933), with the restriction that no one side be correct for more than two consecutive trials. Several different Gellerman series were employed to keep the rats from learning the sequence of trials with extensive training. The doors were removed and reinserted following each trial in order to eliminate auditory cues as to whether the correct stimulus position was still the same or had been shifted for the next trial. The stimuli were washed frequently in order to eliminate olfactory cues. Each daily session consisted of 25 trials.

Two tasks were employed, a brightness discrimination [black $(\mathrm{S}-)$ vs. white $(\mathrm{S}+)$ ] and a pattern discrimination [8 alternating black and white stripes oriented either horizontally $(\mathrm{S}+)$ or vertically $(\mathrm{S}-)$ ]. In the latter, total luminous flux, local luminous flux, and length of contour were equal for both stimuli. Total luminous flux was equated since both stimuli had the same amount of black and white areas $\left(40.50 \mathrm{~cm}^{2}\right)$. Consistent trial-to-trial local flux cues were eliminated by varying which border of each stimulus was black or white on each trial, according to a Gellerman series.

All the rats were trained by the classical method to discriminate - between black and white until they met a criterion of $18 / 20$ correct responses. Two procedures were used to train subjects to discriminate between horizontal and vertical stripes. In the classical procedure, subjects had to discriminate between stimuli which remained constant throughout training and that differed only in the orientation of the stripes. In the fading procedure, subjects were presented with a series of 12 pairs of stimuli in which the discriminanda were gradually modified by fading out the brightness cue (Figure 1). The discriminanda of the 12th pair were identical to the discriminanda presented to the subjects trained classically. Advancement from one step of the fading sequence to the next was conditioned to the performance of three consecutive correct responses. Whenever a subject made two errors in any step of the sequence, it was taken back to the previous step. Each new session began at the last successful step of the previous session; from Step 8 on, bilaterally lesioned subjects were taken back 4 steps at

\begin{tabular}{ccc}
\hline Step & $\begin{array}{c}\text { White area of S+ } \\
\text { and } \\
\text { Black area of S- }\end{array}$ - $\begin{array}{c}\text { Black area of S- } \\
\text { and } \\
\text { area of } S \text {. }\end{array}$ \\
1 & 7740 & 360 \\
2 & 7380 & 720 \\
3 & 7020 & 1080 \\
4 & 6660 & 1440 \\
5 & 6300 & 1800 \\
5 & 5940 & 2160 \\
7 & 5580 & 2520 \\
8 & 5250 & 2880 \\
9 & 4860 & 3240 \\
10 & 4500 & 3600 \\
11 & 4275 & 3825 \\
12 & 4050 & 4050
\end{tabular}

Figure 1. Black and white areas of $\mathrm{S}+$ and $\mathrm{S}-\left(\right.$ in $\left.\mathrm{mm}^{2}\right)$ of the 12-step series used in the fading procedure. On the right, scale drawing of discriminanda, Steps 2, 5, 9, and 12. 
the beginning of each session. For the last step (12th), a criterion of $18 / 20$ correct responses on 2 consecutive days was requiredthe same criterion required by the subjects trained by the classical procedure. All rats were trained up to a maximum of 750 trials.

\section{Procedure}

The rats were randomly assigned to eight groups of five subjects each. The sequence of events for each group is shown in Figure 2. There were three stages of training: Training $1\left(T_{1}\right)$ from Day 1 to Day 7 , Training $2\left(T_{2}\right)$ from Day 18 to Day 22 , and Training 3 $\left(\mathrm{T}_{3}\right)$ from Day 33 on. In each one of the three stages, the subjects of all groups were first trained on the brightness discrimination by a classical procedure, and then on the pattern discrimination by a classical $(\mathrm{Cl})$ or a fading $(\mathrm{Fa})$ procedure. Following Training 1 (Day 8) serial groups (Se) underwent unilateral removal of the visual cortex and, after Training 2 (Day 23), the visual cortex was ablated from the other hemisphere. Simultaneous groups (Si) underwent bilateral removal of the visual cortex in one operation, simultaneous early groups (Si-E) at the time of the first lesion of the Se groups (Day 8) and simultaneous late groups ( $\mathrm{Si}-\mathrm{L}$ ) at the time of the second lesion of the Se groups (Day 23). Control groups (C) were not operated on.

\section{Surgery and Histology}

Surgery was performed under Ketalar ${ }^{R}$ anesthesia $(7.5 \mathrm{mg} / 100 \mathrm{~g})$ and aseptic conditions. The posterior neocortex was exposed after removal of the overlapping bone using a dental drill and reflecting the dura mater. The piece of bone was replaced at the end of surgery. The lesion was intended to include all the visual cortex as defined by cytoarchitectural (Krieg, 1946a, 1946b) (areas 17, 18, and 18a) and electrophysiological (Montero, 1973; Montero, Rojas, $\&$ Torrealba, 1973) analysis. The position and extent of the cortical area to be lesioned were determined by measurements taken relative to the midline suture and to the intersection of the transversal and midsagittal bone sutures (lambda). The lesions extended from the posterior tip of the occipital pole to $4 \mathrm{~mm}$ anterior to lambda and $1.8 \mathrm{~mm}$ from the midsagittal suture to $6.7 \mathrm{~mm}$ laterally. Very small and superficial cortical electrolytic lesions were made to de-

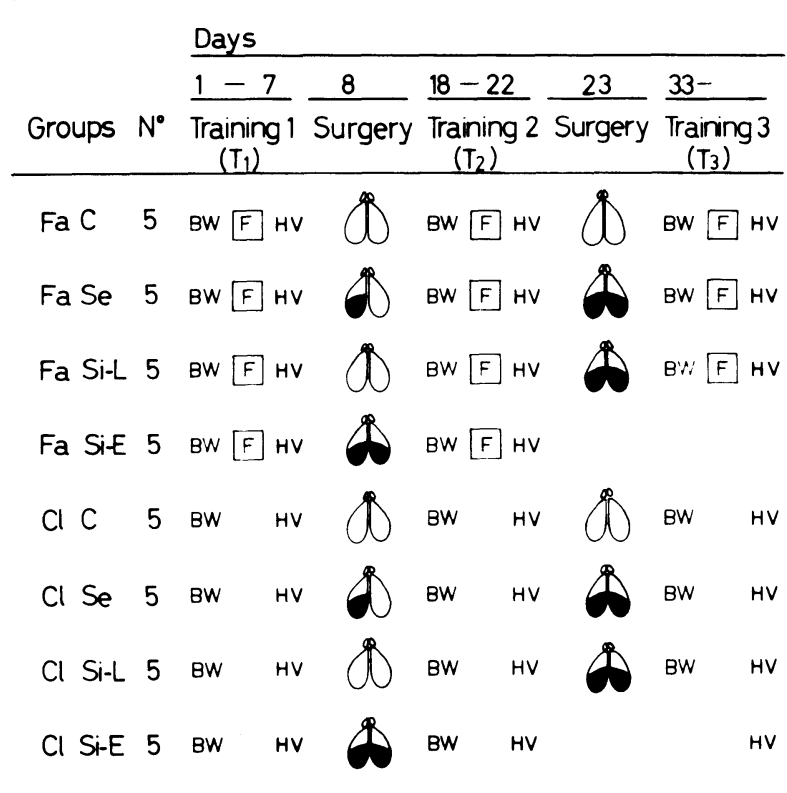

Figure 2. The sequence of events for each group of rats. BW, black vs. white; HV, horizontal vs. vertical; F, fading procedure. fine boundaries along the medial, anterior, and lateral visual cortex. The cortical tissue was removed by subpial suction through a glass pipette with a fine tip.

From 60 to 90 days after the lesions, the rats were given a lethal dose of urethane and were perfused through the left ventricle with normal saline followed by $10 \%$ formol saline; the brain was removed and kept in fixative for 1 month. The posterior two-thirds of the brain were transferred to $30 \%$ sucrose in the same fixative for 2 days and cut as a $30-\mu$ m-thick coronal series with a freezing microtome. Every sixth section was stained with cresyl violet.

The extent of the cortical lesion was determined in three ways. In all animals, the presence of retrograde cell degeneration in the dorsal lateral geniculate nuclei (dLGN) of the thalamus was examined. A reconstruction of each rat's posterior neocortex was made and the lesioned area was compared, superimposing the midline and lateral and posterior borders of the brain on a map of the rat's visual cortex (Montero, Rojas, \& Torrealba, 1973). The cortex surrounding the lesion was examined in Nissl sections for possible regions of normal visual cortex.

\section{RESULTS}

\section{Histology}

Figure 3 shows scale drawings of the lesion reconstructions of four rats of the ClSe, FaSe, ClSi-L, and FaSi-L groups and three rats of the ClSi-E and FaSi-E groups. Lesions were considered to be complete when cortical layers 1-5 had been thoroughly removed. Statistical analysis was made to compare the extent (in $\mathrm{mm}^{2}$ ) of the cortical lesion of each group. No significant differences were found in the extent of the cortical lesion between the two hemispheres for rats in any of the six groups. A two-way analysis of variance $(2 \times 3)$ of lesion size data showed no significant differences between $\mathrm{Fa}$ and $\mathrm{Cl}$ groups or between Se, Si-E, and Si-L groups.

In almost all subjects, the extent of visual cortex removal included all the striate and peristriate visual cortex (areas 17, 18, and 18a of Krieg), as determined by reconstruction of the lesions and examination of retrograde cell degeneration in the $\mathrm{dLGN}$ as well as of cortical tissue cytoarchitecture around the lesion in the Nissl sections. Cytoarchitectural designation of visual and adjacent cortical areas was taken from Krieg (1946a, 1946b). Area 17 had been completely removed in all subjects, as shown by total retrograde cell degeneration of dLGN found in all lesioned subjects. These results were confirmed by superimposing scale drawings of the reconstruction of each subject's lesion on a visual cortex map (Montero et al., 1973). The cortical area 18 in the rat is easily differentiated from the adjacent area 29c. Area 18 was completely included in the cortical lesion of the rats except for Subjects 3 (ClSe), 6 (ClSi-L), and 41 (FaSi-L), which showed some spared tissue. The lateral boundary of the visual cortex was difficult to determine. Probably some tissue was spared in Rats 15 and 18 (FaSe), 5 and 6 (ClSi-L), 41 (FaSi-L), 4 (ClSi-E), and 44 (FaSi-E). As an exception, Rat 20 of the ClSi-E group showed complete sparing of area 18a.

Within each group, no behavioral differences were 


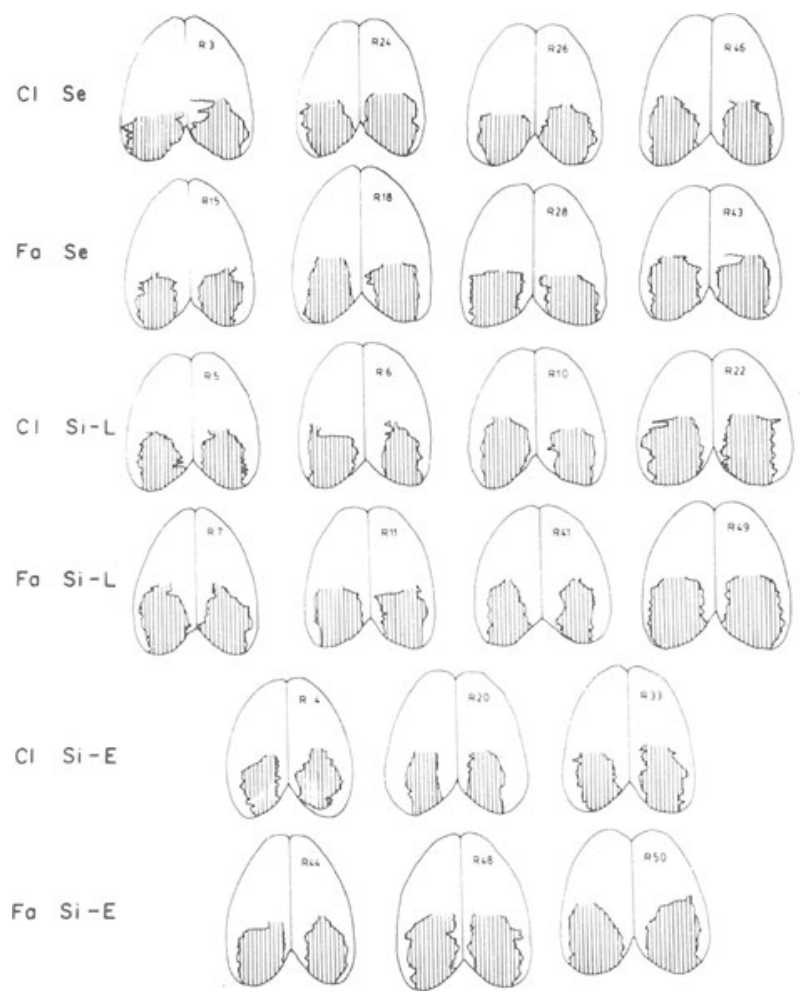

Figure 3. Dorsal views of the brains of 22 of the 30 operated rats showing scale drawings of the visual cortex lesion. For reference to the learning data in Figure 6, each rat's number is indicated in the upper part of the right hemisphere.

found between rats with complete lesion and those that showed a small remnant of either area 18 or area 18a. The performance of Rats 6 (ClSi-L) and 41 (FaSi-L), which had some tissue sparing in both visual peristriate areas, was among the best in their groups; Rat 6 met the $18 / 20$ correct responses criterion once during training. Rat 20, which had an almost intact 18 a peristriate cortical area, was the only simultaneously lesioned subject trained by the classical method that learned the pattern discrimination task.

\section{Behavior}

Figures 4 and 5 present the means and SDs of trial and error scores to the $18 / 20$ criterion for the eight groups on the brightness and pattern discrimination tasks in the three stages of training. In Figure 4, "Fa" refers to groups trained by the fading procedure on the pattern discrimination task. Trial and error scores included the first, but not the second, criterion block. Statistical analyses are reported only for trials when both error and trial measures were in agreement.

\section{Brightness Discrimination}

Training 1. Figure 4 presents the scores for each group before introduction of the experimental vari- ables. Statistical analysis using the Kruskal-Wallis test showed no significant differences between groups.

Training 2. A Kruskal-Wallis test showed significant differences between the trial scores of groups at $T_{2}[H(7)=19.7773, p<.01]$. The analysis of the scores of the $\mathrm{Cl}$ and "Fa" groups as $\mathrm{T}_{2}$ (Figure 4) shows no significant differences as long as the neurological condition was identical, so the groups were rearranged as: normal group ( $\mathrm{ClC}$, " $\mathrm{Fa}$ ' $\mathrm{C}, \mathrm{ClSi}-\mathrm{L}$, "Fa"Si-L), unilateral group (ClSe, "Fa' $\mathrm{Fe}$ ), and bilateral group (ClSi-E, "Fa"Si-E). It should be pointed out that, at $T_{2}$, subjects of the $\mathrm{Si}-\mathrm{L}$ groups were still normal subjects. Normal subjects required fewer trials to criterion than subjects with either unilateral $[\mathrm{t}(18)=2.2135, \mathrm{p}<.04]$ or bilateral lesions $[\mathrm{t}(18)=4.5839, \mathrm{p}<.0002]$; the unilateral group required fewer trials than the bilateral group $[\mathrm{t}(18)=$ $2.7728, \mathrm{p}<.02]$.

Analysis of $T_{1}$ and $T_{2}$ trial scores by " $t$ " tests for dependent groups showed that normal and unilateral groups had savings at $T_{2}$ but that the bilateral group did not [normal group, $\mathrm{t}(19)=11.6247, \mathrm{p}<.0001$; unilateral group, $t(9)=9.9652, p<.0001]$. In spite of the fact that the normal group had a higher mean

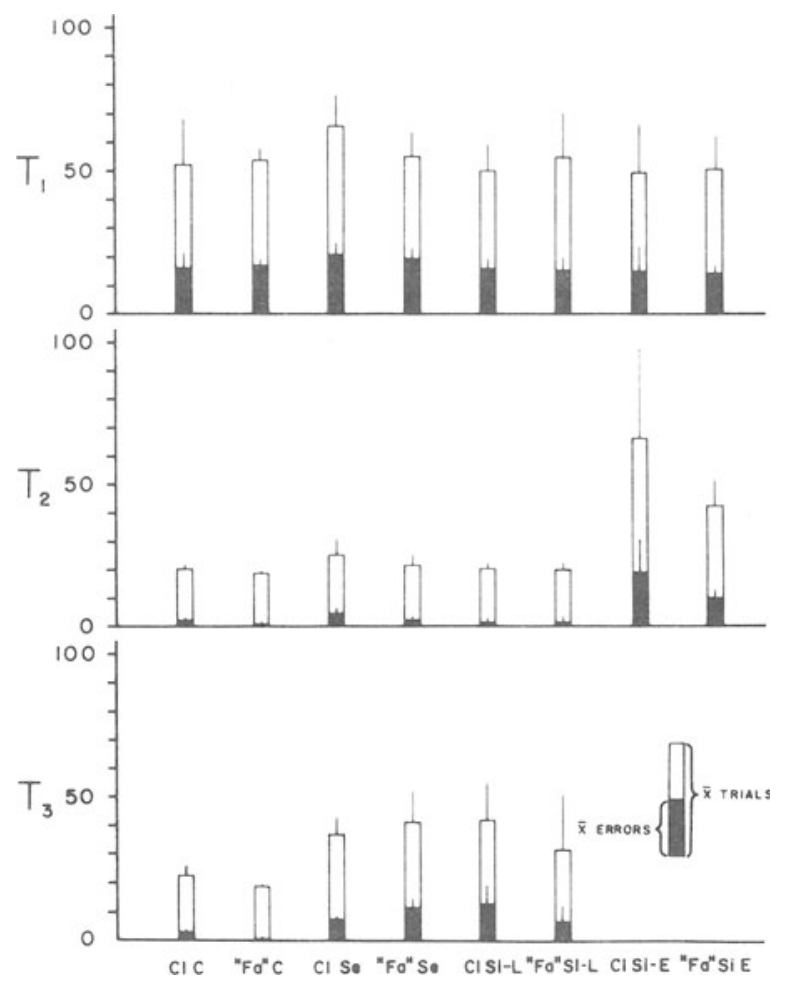

Figure 4. Mean and SD of trial and error scores to the $18 / 20$ criterion for the eight groups on the brightness-discrimination task at the three stages of training. Total area of columns indicates trials; shadowed area indicates errors. The criterion block is included. "Fa" designates the groups trained by the fading procedure on the pattern discrimination. 
percentage of savings scores than the unilateral group, the difference did not reach significance.

In summary, the possible effect of the fading procedure used in pattern discrimination at $T_{1}$ on brightness relearning at $T_{2}$ was nil. The neurological variable influenced the rats' performance in relearning and savings scores.

Training 3. A Kruskal-Wallis test yielded significant differences between trial scores required for all groups at $\mathrm{T}_{3}[\mathrm{H}(5)=16.5597, \mathrm{p}<.01]$. The data were analyzed in order to detect a possible effect of the fading procedure previously used $\left(T_{1}\right.$ and $\left.T_{2}\right)$ in the pattern discrimination on brightness discrimination at $T_{3}$. This effect was evidenced only in terms of error score differences between normal groups. The " $\mathrm{Fa}$ " $\mathrm{C}$ group had significantly fewer errors to criterion than the $\mathrm{ClC}$ group [ $\mathrm{t}(8)=2.846, \mathrm{p}<.04]$. As to the effect of the neurological variable, significant differences between the normal and bilaterally lesioned groups were found. $\mathrm{C}$ groups had fewer trials to criterion than either the Se $[\mathrm{ClC}$ vs. $\mathrm{ClSe}, \mathrm{t}(8)=3.8512, \mathrm{p}<$ .003 ; “Fa'"Se, $\mathrm{t}(8)=3.7939, \mathrm{p}<.005]$ or $\mathrm{Si}$ groups (ClC vs. ClSi-L, t $(8)=2.9005, \mathrm{p}<.008$; “Fa"C vs. "Fa"'Si-L, $\left.{ }^{1} \mathrm{p}<.05\right]$. No significant differences were found between the Se and $\mathrm{Si}$ groups when $\mathrm{T}_{3}$ scores were analyzed. The effect of the surgical procedure used was shown by $t$ test only when $T_{3}$ and $T_{1}$ performances were compared in each group; the Si group had no savings at $\mathrm{T}_{3}$, but $\mathrm{Se} \operatorname{did}[\mathrm{t}(9)=4.0719, \mathrm{p}<$ $.001]$. This serial effect lesion was not consistent, since the Se group did not show a significantly greater percentage of savings than the Si group. $\mathrm{C}$ groups showed savings at $T_{3}$ with respect to $T_{1}[C l C, t(4)=3.9064, p<$ .009 ; "Fa"' $\mathrm{C}, \mathrm{t}(4)=18.6084, \mathrm{p}<.0001]$ and their percentages of savings scores were significantly higher than those of the Se subjects [ClC vs. ClSe, $t(8)=2.5087$, $\mathrm{p}<.05$; "Fa"C vs. "Fa" Se, $\mathrm{t}(8)=7.0781, \mathrm{p}<.01$ ].

Statistical analysis comparing performances of the simultaneously lesioned subjects in the early and late conditions ("Fa" $\mathrm{Si}-\mathrm{E}$ vs. "Fa" $\mathrm{Si}-\mathrm{L}$ and $\mathrm{ClSi}-\mathrm{E}$ vs. "Fa"Si-L) yielded no significant differences.

In summary, the training procedure previously used in the pattern discrimination differentiated only normal groups in brightness performance at $T_{3}$. Relearning scores differentiated only between normal and bilateral subjects, the effect of the surgical procedure being evidenced in savings scores. Early and late conditions proved to be irrelevant for simultaneously lesioned subjects.

\section{Pattern Discrimination}

In the pattern-discrimination task, $\mathrm{Fa}$ and $\mathrm{Cl}$ groups could not be compared in terms of percentage of savings scores, since the methodology used required $\mathrm{Cl}$ groups to perform a minimum of 18 trials and $\mathrm{Fa}$ groups a minimum of 54 trials. Savings scores of $T_{3}$ and $T_{2}$ over $T_{1}$ will be analyzed only by means of $t$ test for dependent groups.
Training 1. Figure 5 shows the mean trial and error scores for normal rats trained by the classical and fading procedures on the pattern-discrimination task. A one-way analysis of variance showed that the groups differed significantly in trials to criterion $[F(7,32)=7.5891, p<.001]$. Subjects trained by fading required significantly more trials than those trained by the classical method $[\mathrm{t}(38)=6.1502, \mathrm{p}<$ $.001]$. However, the groups did not differ in error scores.

Training 2. The statistical analyses performed on the data shown in Figure 5 corresponding to $T_{2}$ assessed the effect of the training procedure ( $\mathrm{Fa}$ vs. $\mathrm{Cl}$ ) and compared the performance of normal (C) and serially lesioned (Se) rats. Since Si-E groups in $T_{2}$ and the Si-L groups in $\mathrm{T}_{3}$ did not differ from each other (ClSi-E vs. ClSi-L and FaSi-E vs. FaSi-L), their performance will be analyzed together in Training 3.

A two-way analysis of variance showed that $\mathrm{Fa}$ groups had more trials $[F(1,16)=137.448, p<.001]$ but fewer errors $[F(1,16)=8.5816, p<.01]$ than the $\mathrm{Cl}$ groups. As to the effect of the neurological variable, unilaterally lesioned groups (Se) required a significantly higher number of trials to criterion than normal groups $(C)[F(1,16)=8.1576, p<.01]$. No interaction effect between lesion and training variables was found at this stage.

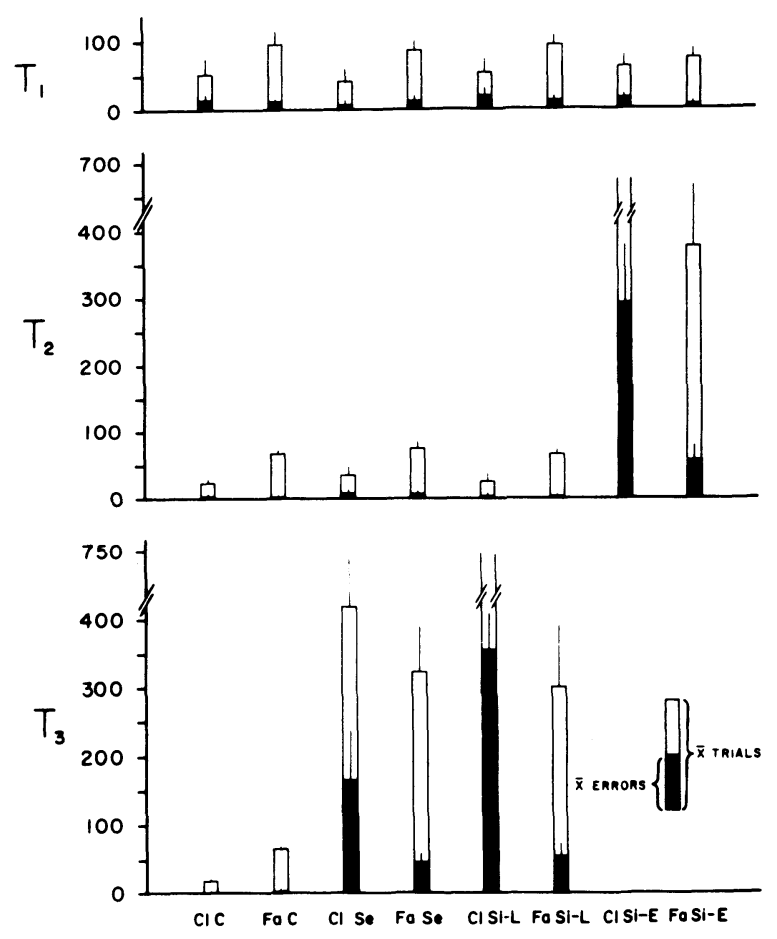

Figure 5. Mean and SD of trial and error scores to the $18 / 20$ criterion or up to 750 trials for the eight groups on the patterndiscrimination task, at the three stages of training. Total area of columns indicates trials; shadowed area indicates errors. Only the first criterion block was included. 
The effect of the unilateral lesion was also shown in savings scores; the $C$ groups showed savings in the number of trials to criterion at $T_{2}$ but the Se groups did not $[\mathrm{ClC}, \mathrm{t}(4)=3.4032, \mathrm{p}<.025 ; \mathrm{FaC}, \mathrm{t}(4)=$ $3.3389, \mathrm{p}<.025]$.

In summary, at $T_{2}$, the fading procedure had a negative effect in terms of more trials but a positive one in terms of fewer errors. The neurological variable influenced both relearning and savings scores.

Training 3. As shown in Figure 6, none of the simultaneously lesioned subjects trained by the $\mathrm{Cl}$ method (ClSi-L and ClSi-E) met the $18 / 20$ criterion

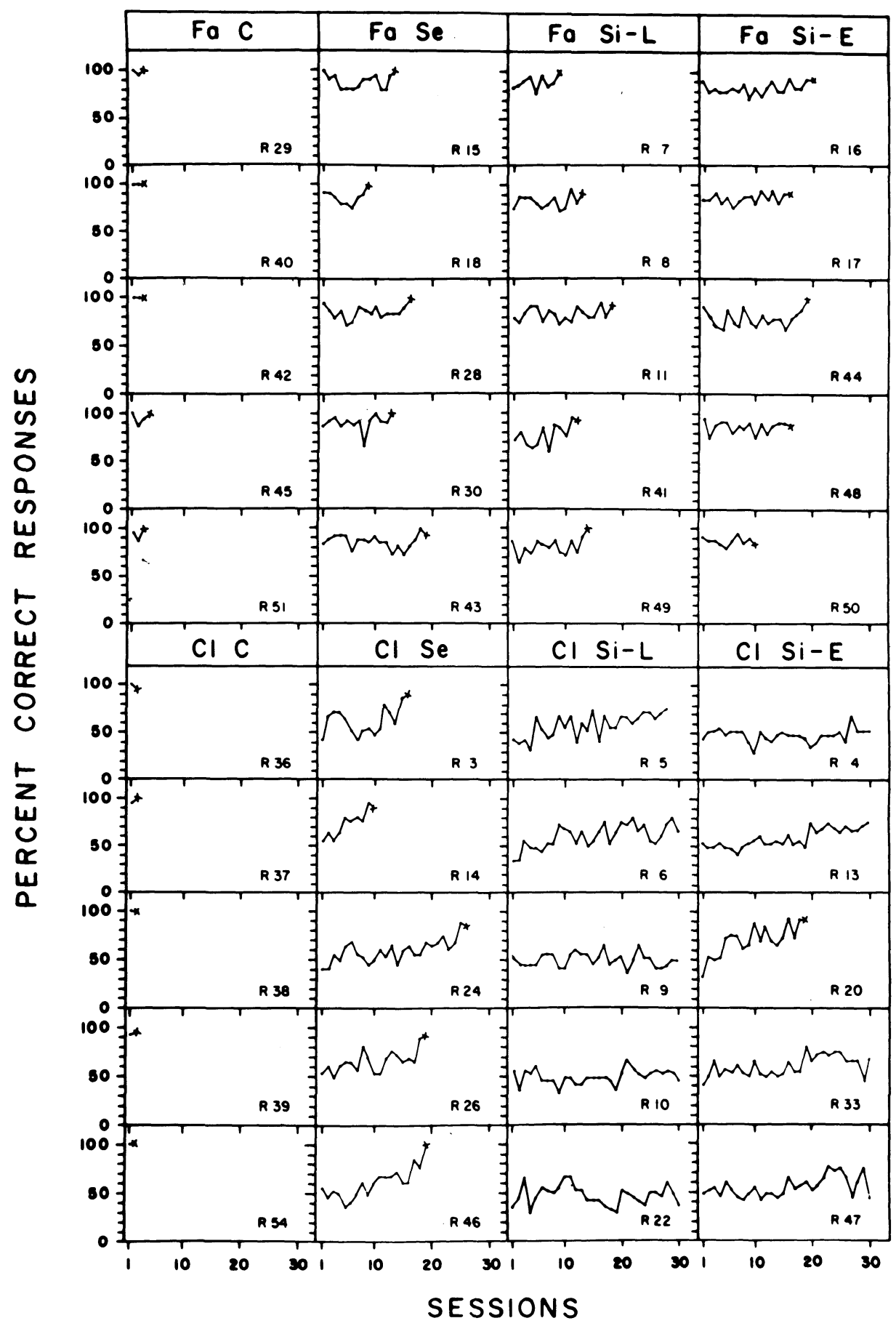

Figure 6. Percent of correct responses along sessions for each rat on the pattern-discrimination task at Training 3 . The cross at the end of each learning curve signals the session in which the second $18 / 20$ criterion was reached. 
in two consecutive sessions up to a maximum of 750 trials, except for Rat 20. However, all of the subjects trained by the fading procedure (FaSi-L and FaSi-E) learned the pattern discrimination task in a mean of 342.7 trials to criterion.

Except for Rats 13, 20, and 33 of the ClSi-E group and Rat 6 of the ClSi-L group, the simultaneously lesioned subjects trained by the classical procedure clearly maintained performance at chance level up to the maximum of 750 trials. Rats 6 and 33 met the $18 / 20$ criterion once during training, but failed to maintain this level of performance in the following session. Almost all simultaneously and serially lesioned subjects trained by the fading procedure (FaSi-L, FaSi-E, and FaSe) had $70 \%$ or above correct responses throughout training. Serially lesioned rats trained by the classical procedure (ClSe) initially had a low percentage of correct responses which gradually improved along sessions. Besides the qualitative analyses just mentioned, statistical analyses were performed at this stage to assess: (1) training variable effects in lesioned and normal rats, and (2) neurological variable effects, comparing (a) bilaterally lesioned vs. normal groups and (b) serially vs. simultaneously lesioned subjects.

Statistical comparisons were made only between the $\mathrm{FaSe}, \mathrm{FaSi}$, and $\mathrm{ClSe}$ groups, since, as already reported, the ClSi group did not meet criterion and it was arbitrarily decided to suspend training at $\mathbf{7 5 0}$ trials. Therefore, a two-way analysis of variance could not be carried out to study the interaction effect between the training and surgical variables (Guilford, 1973).

(1) The effect of training procedure was shown in serially lesioned subjects in error scores; the FaSe group had significantly fewer errors $[t(8)=3.4037$, $\mathrm{p}<.05]$ than the ClSe group, although no differences in number of trials to criterion were found between them. As to the effect of training procedure on normal subjects, a test showed that the $\mathrm{FaCl}$ group required more trials to criterion than the $\mathrm{ClC}$ group $[t(8)=32.9248, p<.0005]$ and that there were no differences in terms of error scores. (2a) The effect of bilateral lesions made either serially or simultaneously were clearly shown, as expected. Normal (C) groups required significantly fewer trials than did the $\mathrm{Se}$ and $\mathrm{Si}$ groups when using the same training procedure [ClC vs. $\mathrm{ClSe}, \mathrm{t}(8)=6.0573, \mathrm{p}<.001 ; \mathrm{FaC}$ vs. FaSe, $\mathrm{t}(8)=8.1137, \mathrm{p}<.0001 ; \mathrm{FaC}$ vs. FaSi-L, $t(8)=5.9829, p<.001]$. Savings were also studied by comparing $T_{3}$ vs. $T_{1}$ performances. The results showed that unoperated $(C)$ groups saved in number of trials in $\mathrm{T}_{3}[\mathrm{ClC}, \mathrm{t}(4)=2.9084, \mathrm{p}<.025 ; \mathrm{FaC}$, $\mathrm{t}(4)=4.1584, \mathrm{p}<.02$ ]; however, the lesioned groups (Se and $\mathrm{Si}$ ) did not. (2b) No differential effect of serial or simultaneous lesions was found in $\mathrm{Fa}$ subjects.

In summary, at $T_{3}$, the training and surgical pro- cedures proved to be critical for the relearning of the pattern-discrimination tasks.

\section{DISCUSSION}

After simultaneous damage to striate and extrastriate visual cortex (areas 17,18, and 18a), rats were able to relearn the $\mathrm{H}-\mathrm{V}$ pattern-discrimination task when trained by the fading procedure. When the rats were trained by the classical procedure, our results were in accordance with those of numerous previous experiments (Bauer \& Hughes, 1970; Bland \& Cooper, 1969; Braun et al., 1970; Lashley, 1931; Spear \& Barbas, 1975; Thompson, 1969); they showed that rats after one-step damage to the visual cortex fail to relearn the $\mathrm{H}-\mathrm{V}$ task. In general, our results in the brightness (B-W) and pattern (H-V) discrimination tasks using the classical training procedure in normal, unilateral, and bilateral (serially or simultaneously lesioned) rats replicated results of previous studies (Barbas \& Spear, 1976; Bauer \& Cooper, 1964; Bland \& Cooper, 1969; Braun et al., 1970; Dru et al., 1975a, 1975b; Glendenning, 1972; Hamilton \& Trichler, 1968; Lashley, 1931, 1935, 1937; Le Vere \& Morlock, 1973; Meyer et al., 1966; Petrinovich \& Bliss, 1966; Petrinovich \& Carew, 1969; Scheff et al., 1977; Scheff \& Wright, 1977; Spear \& Barbas, 1975; Thompson, 1960, 1969).

In addition, our data showed a tendency towards interaction between surgical and training variables. The fading procedure reduced error and trial scores relatively more for simultaneously than for serially lesioned subjects.

\section{Brightness Discrimination}

The effect of the unilateral lesions was clearly shown in $T_{2}$, since normal rats performed significantly better than unilateral rats. Normal and unilateral rats both showed significant savings in $T_{2}$ compared with $T_{1}$ performance. Although normal subjects had a higher savings percentage than did unilateral subjects, the difference was not significant, as expected in accordance with a previous report (Barbas \& Spear, 1976).

On the final retention test $\left(T_{3}\right)$, our serially lesioned rats showed savings over their $T_{1}$ performance, but simultaneous rats did not. This serial lesion effect has already been reported (Barbas \& Spear, 1976; Glendenning, 1972; Petrinovich \& Bliss, 1966; Petrinovich \& Carew, 1969; Scheff et al., 1977; Scheff \& Wright, 1977; Thompson, 1960).

The performance of normal rats on the B-W discrimination task was differentially affected by the previous use of fading or classical procedures to train the subjects on the $\mathrm{H}-\mathrm{V}$ task. That is, rats trained on $H-V$ by fading in $T_{1}$ and $T_{2}$ had fewer errors on B-W 
at $T_{3}$ than did rats trained on $H-V$ by the classical procedure in $T_{1}$ and $T_{2}$. This effect might be due to overtraining of the fading subjects on the brightness cue and/or a different history of errors in each group. First, fading subjects were trained on the pattern discrimination with total flux cues present in 11 of the 12 steps. Second, subjects trained by fading made fewer errors in their pattern-discrimination performance at $T_{1}$ and $T_{2}$ than did those trained by classical procedures, and there is evidence that a different history of errors affects subsequent performance (Aronsohn et al., 1978; Terrace, 1963b). Specifically, Aronsohn et al. (1978) have shown that normal rats trained by the classical method learn a visual pattern discrimination reversal task with fewer errors when previously trained with a fading rather than a classical method during acquisition.

\section{Pattern Discrimination}

As expected, those of our rats which had been subjected to a simultaneous bilateral lesion and trained by the classical method did not meet the learning criterion required in the $\mathrm{H}-\mathrm{V}$ test up to 750 trials, except for one rat (Rat 20). Rat 20 had the smallest lesion in which the lateral extrastriate visual cortex (area 18a) was bilaterally spared. There is evidence from Hughes (1977) that rats with sparing of the peristriate visual cortex (areas 18 and 18a) can master an oblique-stripe pattern discrimination, a more difficult task than the one used in the present work (Lavond, Hata, Gray, Geckler, Meyer, \& Meyer, 1978).

The pattern-discrimination results for normal and bilaterally lesioned rats trained by the classical method are in accordance with those obtained by Spear and Barbas (1975) in very similar experimental conditions. Unilateral rats (ClSe), however, showed no significant savings in $T_{2}$ with respect to preoperative performance $\left(T_{1}\right)$, as did unilateral rats in Spear's study.

As to one of the main questions of the present work, the effect of the fading procedure, it was found that subjects trained by this method differ from the classically trained subjects in all stages of training. Moreover, the effect of the fading procedure appears to vary according to the neurological condition of the rat. For simultaneously bilaterally lesioned subjects, fading was critical in allowing them to relearn the $\mathrm{H}-\mathrm{V}$ pattern discrimination. For serial bilateral and unilateral rats, a facilitating effect was found only in error scores. Furthermore, unilateral rats trained by fading required more trials to criterion than the classical ones. For normal subjects, no beneficial effect at all was obtained when fading was employed; they had more trials than classically trained rats and the groups did not differ in error scores. The $\mathrm{H}-\mathrm{V}$ task proved to have, as measured by the classi- cal training method, a decreasing degree of difficulty as the rats were subjected to a less severe neurological injury. Hence, the fading procedure used in the present experiment proved to be less effective as the difficulty of the task decreased for the subjects. In normal subjects, it has been frequently observed (Guic et al., 1978; Schusterman, 1966; Terrace, 1966) that, in order to acquire a discrimination task with a minimum of trials and errors, it is critical to adjust the fading graduation to the specific task difficulty for the subjects. Our experimental design was not aimed at finding the most effective series of the fading procedure for each one of the neurological conditions. In the present study, the same fading series of stimuli was used for all groups, and it proved to be best suited to the simultaneous bilateral rats.

We believe that, for simultaneously bilaterally lesioned subjects to learn the $\mathrm{H}-\mathrm{V}$ task, the critical aspects of the fading procedure were: the use of the brightness cue in facilitating the acquisition of the pattern task, since this cue is easily discriminated by visually decorticated rats, and the process of reducing brightness differences in a graduated sequence slow enough for simultaneous bilateral rats.

Recently, Dineen and Keating (1981) have shown, in destriated monkeys, that an initially large difference in total luminous flux allowed some of their subjects to reacquire a pattern-discrimination task. Further comparisons between the present study and theirs cannot be made, since their subjects, lesions, and training procedure differ from ours.

It should be pointed out that two of our ClSi rats (Rats 6 and 33) reached the $18 / 20$ criterion once during training, but the performance was not maintained in the following sessions. The same observation was reported by Spear and Barbas (1975) on two rats subjected to conditions similar to those of our ClSi rats. Thus, it cannot be ruled out that, after a longer period of training than the one used in the present work, ClSi rats could eventually be able to solve the $\mathrm{H}-\mathrm{V}$ task at a reliable level of performance. Cats (Baumann \& Spear, 1977a, 1977b; Spear \& Braun, 1969; Wood, Spear, \& Braun, 1974) and rabbits (Moore \& Murphy, 1976) with extensive simultaneous visual cortex lesions have shown the capacity to relearn the $\mathrm{H}-\mathrm{V}$ task when trained by the classical method if very extensive training on the problem was given. With respect to other pattern-discrimination tasks that can be solved by simultaneously visually decorticated rats, they differ in total luminous flux, local luminous flux, or length of contour (Cowey \& Weiskrantz, 1971; Llewellyn, Lowes, \& Isaacson, 1969; Mize, Wetzel: \& Thompson, 1971), cues that are much more con. spicuous than the local and momentary flux cue po. tentially present in the H-V problem.

Which cues are utilized and what neural mecha nisms are involved in the recovery of pattern discrim ination by subjects with extensive visual cortex dam 
age is yet unsettled. Numerous previous works (Bauer \& Cooper, 1964; Bland \& Cooper, 1970; Cooper, Blochert, Gillespie, \& Miller, 1972; Lavond et al., 1978; Murphy \& Chow, 1974; Schilder, Pasik, \& Pasik, 1967, 1971, 1972; Spear, 1979; Spear \& Baumann, 1979; Spear \& Braun, 1969; Weiskrantz, 1963; Winans, 1971) have discussed the question of whether subjects use the same cues or different ones to solve a visual discrimination task before and after a visual cortex injury.

In the case of the H-V task, besides the differences in the spatial array of light and dark aieas, as suggested by several authors (Dalby, Meyer, \& Meyer, 1970; Lavond et al., 1978; Meyer \& Meyer, 1977; Murphy \& Chow, 1974; Ritchie, Meyer, \& Meyer, 1976; Spear, 1979; Spear \& Braun, 1969; Wood et al., 1974), differences in local and momentary luminous flux that would become evident when the animals scan the stimuli horizontally are potentially present. Subjects without visual cortex would use this latter cue to solve the H-V task, while normal subjects would use true pattern cues (Murphy \& Chow, 1974; Spear \& Braun, 1969). However, there is no consensus on this point; a work (Baumann \& Spear, 1977a) using cats shows no positive evidence to support this notion. The authors concluded that cats without visual cortex are capable of recovering at least some form of spatial pattern vision using cues similar to those used by normal subjects. In our experimental situation, the fading procedure would allow our $\mathrm{FaSi}$ rats to transfer stimulus control from total to either local and momentary differences of luminous flux or to a spatial array of light and dark areas.

The postoperative relearning of the $\mathrm{H}-\mathrm{V}$ problem could be essentially a function of subcortical visual structures, as traditionally proposed (Lashley, 1931), or it could be a function of the cortical areas beyond visual areas 17,18 , and $18 \mathrm{a}$. Perhaps area 20 may play a role in visually guided behavior, since it receives inputs from the nucleous lateralis posterior of the thalamus that are believed to be visual in nature (Hughes, 1977).

The other purpose of the present work was to study the interaction effect between training and surgical variables on the performance of rats without visual cortex. As mentioned in the results, it was not possible to perform the appropriate statistical analysis, so the possible interaction will be discussed on the basis of data presented in Figure 7. This figure shows a plot of the means so as to demonstrate the relationship between scores and training methods in the Se vs. Si surgical procedures. Data depicted show a fairly obvious main effect for "training" from the downward slope of each line; they also show a main effect for "surgery," for classical (a vs. c and e vs. g) but not for fading (b vs. $d$ and $f$ vs. h) subjects. The differences in the slopes between lines $a b$ and $c d$ or lines ef and gh show that the training and surgical

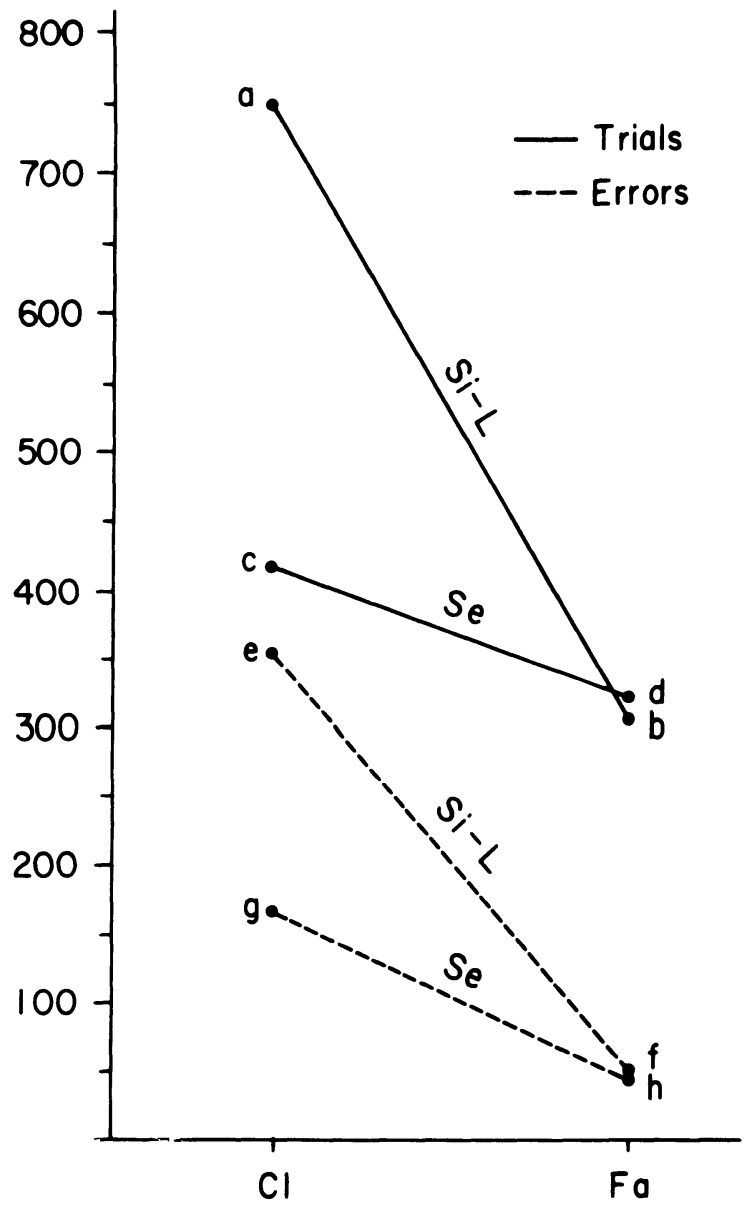

Figure 7. Mean trial and error scores to reattain the $18 / 20$ criterion or up to 750 trials at Training 3 for the Si-L and Se groups, with scores presented separately for $\mathrm{Cl}$ and $\mathrm{Fa}$ trained groups.

variables interact; if there were no interaction, both pairs of lines would be parallel. This interaction effect means that there was no linear addition of both facilitating effects; the $\mathrm{Fa}$ procedure reduced trial and error scores relatively more for $\mathrm{Si}$ than for $\mathrm{Se}$ subjects, as compared with the classical procedure.

One possible explanation for the interaction could be the use of the same fading series for all groups. As already discussed, the graduation of the series used was more effective for those subjects for which the task was more difficult, as measured by the results of the classical method. Another explanation could be that the Se and Si rats are able to relearn the H-V task by means of a different mechanism of recovery or at least by mechanisms that are differentially affected by the Fa procedure used.

\section{REFERENCES}

Aronsohn, S., Castillo, O., \& Pinto-Hamuy, T. Fading procedure effects on a visual pattern discrimination reversal in the albino rat. Animal Learning \& Behavior, 1978, 6, 72-75.

BARBAS, H., \& SPEAR, P. D. Effects of serial unilateral and serial 
bilateral visual cortex lesions on brightness discrimination relearning in rats. Journal of Comparative and Physiological Psychology, 1976, 90, 279-292.

Barlow, D. H., \& Agras, W. S. Fading to increase heterosexual responsiveness in homosexuals. Journal of Applied Behavior Analysis, 1973, 6, 435-441.

Bauer, J. H., \& CoOper, R. M. Effects of posterior cortical lesions on performance of a brightness discrimination task. Journal of Comparative Physiological Psychology, 1964, 58, 84-92.

BAUER, J. H., \& Hughes, K. R. Visual and non-visual behaviors of the rat after neonatal and adult posterior neocortical lesions. Physiology \& Behavior, 1970, 5, 427-441.

BaumanN, T. P., \& Spe AR, P. D. Evidence for recovery of spatial pattern vision by cats with visual cortex damage. Experimental Neurology, 1977, 57, 603-612. (a)

Baumann, T. P., \& Spe AR, P. D. Role of the lateral suprasylvian visual area in behavioral recovery from effects of visual cortex damage in cats. Brain Research, 1977, 138, 445-468. (b)

Bland, B. H., \& Cooper, R. M. Posterior neodecortication in the rat: Age of operation and experience. Journal of Comparative Physiological Psychology, 1969, 69, 345-354.

Bland, B. H., \& Cooper, R. M. Experience and vision of the posterior neodecorticated rat. Physiology \& Behavior, 1970, 5, 211-214.

Braun, J. J., Lundy, E. G., \& McCarThy, F. V. Depth discrimination in rats following removal of visual neocortex. Brain $R e$ search, 1970, 20, 283-291.

Brown, C. H., \& Rilling, M. E. Stimulus delay and the reduction of errors in the transfer of stimulus control. Animal Learning \& Behavior, 1975, 3, 21-27.

Cooper, R. M., Blochert, K. P., Gillespie, L. A., \& Miller, L. G. Translucent occluders and lesions of posterior neocortex in the rat. Physiology \& Behavior, 1972, 8, 693-698.

COREY, J. C., \& Shamow, J. C. The effect of fading on the acquisition and retention of oral reading. Journal of Applied Behavior Analysis, 1973, 5, 311-315.

Cowey, A., \& Weiskrantz, L. Contour discrimination in rats after frontal and striate cortical ablations. Brain Research, 1971, 30, 241-252.

Dalby, D. A., Meyer, D. R., \& Meyer, P. M. Effects of occipital neocortical lesions upon visual discrimination in the cat. Physiology \& Behavior, 1970, 5, 727-734.

Dineen, J., \& Keating, E. G. The primate visual system after bilateral removal of striate cortex. Experimental Brain Research, 1981, 41, 337-345.

Dorry, G. H. Attentional model for the effectiveness of fading in training reading vocabulary with retarded persons. American Journal of Mental Deficiency, 1976, 81, 271-279.

Dru, D., W alker, J. B., \& W Alker, J. P. Recovery of pattern vision following serial lesions of striate cortex in rats. Brain $R e$ search, 1975, 88, 353-356. (a)

Dru, D., Walke R, J. P., \& Walker, J. B. Self-produced locomotion restores visual capacity after striate lesions. Science, 1975, 187, 265-266. (b)

Ellen, P., Dorsett, P. G., \& Richardson, W. K. The effect of cue-fading on the DRL performance of septal and normal rats. Physiological Psychology, 1977, 5, 469-476.

Finger, S., Walbran, B., \& Stein, D. Brain damage and behavioral recovery: Serial lesion phenomena. Brain Research, 1973, 63, 1-18.

Gellerman, L., JR. Chance orders of alternating stimuli in visual discrimination experiments. Journal of Genetic Psychology, 1933, 42, 206-208.

GLENDENNING, R. L. Effects of training between two unilateral lesions of visual cortex upon ultimate retention of black white discrimination habits by rats. Journal of Comparative and Physiological Psychology, 1972, 80, 216-229.

Guić, E., Aronsohn, S., Gormaz, A., \& Pinto-Hamuy, T. Fading procedure modifying one or both stimuli and their effects on visual discrimination learning in rats. Archivos de Biologia y Medicina Experimentales, 1978, 11, R-79.

GUILFORD, J. P. Fundamental statistics in psychology and education. New York: McGraw-Hill, 1973.

Hamilton, D. R., \& Treichle R, F. R. Multiple stimulus dimensions in brightness discrimination learning by rats with striate lesions. Journal of Comparative and Physiological Psychology, 1968, 66, 363-368.

Horel, J. A., Bettinger, L. A., Royce, G. J., \& Meyer, D. R. Role of the neocortex in the learning and relearning of two visual habits in the rat. Journal of Comparative and Physiological Psychology, 1966, 61, 66-78.

Hughes, H. C. Anatomical and neurobehavioral investigations concerning the thalamo-cortical organization of the rat's visual system. Journal of Comparative Neurology, 1977, 175, 311-336.

KRIEG, W. J. S. Connections of the cerebral cortex. I. The albino rat. A. Topography of the cortical areas. Journal of Comparative Neurology, 1946, 84, 221-276. (a)

KRIEG, W. J. S. Connections of the cerebral cortex. I. The albino rat. B. Structure of the cortical areas. Journal of Comparative Neurology, 1946, 84, 277-323. (b)

LASHLEY, K. S. The mechanism of vision: IV. The cerebral areas necessary for pattern vision in the rat. Journal of Comparative Neurology, 1931, 53, 419-478.

LASHLEY, K. S. The mechanism of vision: XII. Nervous structures concerned in the acquisition and retention of habits based on reactions to light. Comparative Psychology Monographs, 1935, 11, 43-79.

LASHLEY, K. S. The mechanism of vision: XIII. Cerebral function of discrimination of brightness when detail vision is controlled. Journal of Comparative Neurology, 1937, 66, 471-480.

Lavond, D., Hata, M. G., Gray, T. S., Geckler, C. L., Meyer, P. M., \& MEYER, D. R. Visual form perception is a function of the visual cortex. Physiological Psychology, 1978, 6, 471-477.

LAWRENCE, D. H. The transfer of a discrimination along a continuum. Journal of Comparative and Physiological Psychology, 1952, 45, 511-516.

LEVERE, T. E., \& Morlock, G. W. Nature of visual recovery following posterior neodecortication in the hooded rat. Journal of Comparative and Physiological Psychology, 1973, 83, 62-67.

Llewellyn, D., Lowes, G., \& IsaAcson, R. L. Visually mediated behavior following neocortical destruction in the rat. Journal of Comparative and Physiological Psychology, 1969, 69, 25-32.

MacDonald, J. S., \& Marcucella, H. Cross-modal transfer of stimulus control in the albino rat: A stimulus delay procedure. Animal Learning \& Behavior, 1976, 4, 341-346.

May, R., \& MacPherson, D. Size discrimination in children facilitated by changes in task difficulty. Journal of Comparative and Physiological Psychology, 1971, 75, 453-458.

Meyer, D. R., \& MEYer, P. M. Dynamics and bases of recoveries of function after injuries to the cerebral cortex. Physiological Psychology, 1977, 5, 133-165.

Meyer, D. R., Yutzey, D. A., \& Meyer, P. M. Effects of neocortical ablations on relearning of a black-white discrimination habit by two strains of rats. Journal of Comparative and Physiological Psychology, 1966, 61, 83-86.

Mize, R. R., Wetzel, A. B., \& Thompson, V. E. Contour discrimination in the rat following removal of posterior neocortex. Physiology \& Behavior, 1971, 6, 241-246.

Monte Ro, V. M. Evoked responses in the rat's visual cortex to contralateral, ipsilateral and restricted photic stimulation. Brain Research, 1973, 53, 192-196.

Montero, V. M., Rojas, A., \& Torrealba, F. Retinotopic organization of striate and peristriate visual cortex in the albino rat. Brain Research, 1973, 53, 257-281.

Moore, R., \& Goldiamond, I. Errorless establishment of visual discrimination using fading procedures. Journal of the Experimental Analysis of Behavior, 1964, 7, 269-272.

Moore, D. T., \& Murphy, E. H. Differential effects of two 
cortical lesions in the rabbit. Experimental Neurology, 1976, 53, 21-30.

Murphy, E. H., \& Chow, K. L. Effects of striate and occipital cortical lesions on visual discrimination in the rabbit. Experimental Neurology, 1974, 42, 78-88.

Petrinovich, L., \& Bliss, D. Retention of a learned brightness discrimination following ablations of the occipital cortex in the rat. Journal of Comparative and Physiological Psychology, 1966, 61, 136-138.

PETRINOVICH, L., \& CAREW, T. J. Interaction of neocortical lesion size and interoperative experience in retention of a learned brightness discrimination. Journal of Comparative and Physiological Psychology, 1969, 68, 451-454.

Ritchie, G. D., \& Meyer, P. M., \& Meyer, D. R. Residual spatial vision of cats with lesions of the visual cortex. Experimental Neurology, 1976, 53, 227-253.

SchefF, S. W., \& Wright, D. C. Behavioral and electrophysiological evidence for cortical reorganization of function in rats with serial lesions of the visual cortex. Physiological Psychology, 1977, 5, 103-107.

SCHEFF, S. W., Wright, D. C., Morgan, W. K., \& Powers, R. B. The differential effects of additional cortical lesions in rats with single or multiple stage lesions of the visual cortex. Physiological Psychology, 1977, 5, 97-102.

Schilder, P., Pasik, P., \& Pasik, T. Total luminous flux: A possible response determinant for the normal monkey. Science, 1967, 158, 806-809.

Schilder, P., Pasik, T., \& Pasik, P. Extrageniculostriate vision in the monkey: II. Demonstration of brightness discrimination. Brain Research, 1971, 32, 383-398.

Schilder, P., Pasik, P., \& Pasik, T. Extrageniculostriate vision in the monkey: III. Circle vs triangle and "red vs green" discrimination. Experimental Brain Research, 1972, 14, 436-448.

Schlosberg, H., \& Solomon, R. L. Latency of response in a choice discrimination. Journal of Experimental Psychology, 1943, 51, 393-395.

Schuste Rman, R. Serial discrimination-reversal learning with and without errors by the California sea lion. Journal of the Experimental Analysis of Behavior, 1966, 9, 593-600.

Schusterman, R. Attention shift and errorless reversal learning by the California sea lion. Science, 1967, 156, 833-835.

Sidman, M., \& Stoddard, L. The effectiveness of fading in programming a simultaneous form discrimination for retarded children. Journal of the Experimental Analysis of Behavior, 1967, 10, 3-15.

Siggel, S. Diseño experimental no paramétrico. México: Trillas, 1970.

SPEAR, P. D. Behavioral and neurophysiological consequences of visual cortex damage: Mechanisms of recovery. In J. M. Sprague \& A. N. Epstein (Eds.), Progress in psychobiology and physiological psychology (Vol. 8). New York: Academic Press, 1979.

SPEAR, P. D., \& BARBAS, H. Recovery of pattën discrimination ability in rats receiving serial or one-stage visual cortex lesions. Brain Research, 1975, 94, 337-346.
Spear, P. D., \& Baumann, T. P. Neurophysiological mechanism of recovery from visual cortex damage in cats: Properties of lateral suprasylvian visual area neurons following behavioral recovery. Experimental Brain Research, 1979, 35, 177-192.

Spear, P. D., \& Braun, J. J. Pattern discrimination following removal of visual neocortex in the cat. Experimental Neurology, 1969, 25, 331-348.

Stettne R, L. J., \& Matyniak, K. A. The use of stimulus fading in assessing behavioral deficit produced by brain damage. Physiology \& Behavior, 1969, 4, 858-861.

Terrace, H. S. Discrimination learning with and without errors. Journal of the Experimental Analysis of Behavior, 1963, 6, 1-27. (a)

Terrace, H. S. Errorless transfer of a discrimination across two continua. Journal of the Experimental Analysis of Behavior, 1963, 6, 223-232. (b)

TERRACE, H. S. Stimulus control. In W. K. Honig (Ed.), Operant behavior: Areas of research and application. New York: Meredith, 1966.

Tномpson, R. Retention of a brightness discrimination following neocortical damage in the rat. Journal of Comparative and Physiological Psychology, 1960, 53, 212-215.

Thompson, R. Localization of the "visual memory system" in the white rat. Journal of Comparative and Physiological Psychology Monograph, 1969, 69, 1-29.

Thompson, R., \& Bryant, H. J. Memory as affected by activity of the relevant receptor. Psychological Report, 1955, 1, 393-400.

Touchette, P. E. The effects of gradual stimulus change on the acquisition of a simple discrimination in severely retarded boys. Journal of the Experimental Analysis of Behavior, 1968, 11, 39-48.

Weiskrantz, L. Contour discrimination in a young monkey with striate cortex ablation. Neuropsychologia, 1963, 1, 145-164.

Winans, S. S. Visual cues used by normal and visual-decorticated cats to discriminate figures of equal luminous flux. Journal of Comparative and Physiological Psychology, 1971, 74, 167-178.

Wood, C. C., Spear, P. D., \& Braun, J. J. Effects of sequential lesions of suprasylvian gyri and visual cortex on pattern discrimination in the cat. Brain Research, 1974, 66, 443-466.

Wulbert, M., Nyman, A., Snow, D., \& Owen, T. The efficacy of stimulus fading and contingency management in the treatment of selective mutism: A case study. Journal of Applied Behavior Analysis, 1973, 6, 441-453.

\section{NOTE}

1. The randomization test for independent samples (Siegel, 1970) was used instead of the $t$ test since homogeneity of the variance in the populations involved could not be assumed.

(Manuscript received February 10, 1982; revision accepted for publication May 17, 1982.) 